\title{
Satisfaction Perception of Indoor Environment of Low-cost Housing: A case study of Flat Taman Desa Sentosa
}

\author{
Mohd Farid Mohamed ${ }^{1}$, Wardah Fatimah Mohammad Yusoff ${ }^{2}$, Tito Maulana Iman Pratama ${ }^{3}$, \\ Sudharshan N. Raman ${ }^{4}$ \\ ${ }^{1,2,3,4}$ Department of Architecture, Universiti Kebangsaan Malaysia, 43600 UKM Bangi, Selangor, \\ Malaysia
}

\begin{abstract}
Low-Cost Flat Housing is the housing for low income group.. It began with a flat which has two bedrooms in each unit, then it was increased three bedrooms. The three bedrooms flat has to fit the floor area of 650 square feet, in which was later revised to 700 square feet. Small overall floor area which comes with small budget allocated for its construction, could lead to poor indoor environmental quality (IEQ) in low-cost flat, if not properly designed. This paper discusses on the occupants' satisfaction perception of IEQ of a low cost flat in Kampung Teras Jernang, Selangor. The methodologies used in this study are site observation and questionnaire survey. This study concludes that the IEQ in the selected low-cost flat has acceptably fulfilled the needs and quality required by the occupants. However, there is a factor that the building occupants have expressed poor perception, which is the noise pollution.
\end{abstract}

\section{Introduction}

Low-cost housing which is developed for low income group is an important housing category in Malaysia where one of its initial objective is to overcome the squatter problem. Due to its importance, there are various studies were conducted on the low-cost housing in Malaysia such as by Mohit et al. [1], Abdul Ghani [2] and Idrus and Ho [3].

Among all high-density apartment building types with three bedrooms, low-cost flat has the lowest total floor area with the minimum floor area of 650 square feet. Currently, the minimum floor area for three bedrooms low-cost flat has been increased to 700 square feet [4]. With such a small floor area that provides three bedrooms with its other essential spaces of a home, each space has a very limited floor area, thus could results in poor indoor environmental quality. But, it is not just the limited floor area that could affect the quality of indoor environmental quality (IEQ) of low-cost flat; among other factors are workmanship, plan layout, opening size and quality of materials.

Since a low-cost flat is the high-density housing type that only complies with the minimum standard requirements by the authority, the risk of poor indoor environment quality is much higher compared to the other types. Therefore, it is common to have a general perception that the IEQ of a low-cost flat is poor. However, does this perception is accurate among the occupants of low-cost flat? In order to investigate this, a study is completed to achieve the objective of this paper, which is to obtain the perception of the occupants of low-cost flat on the indoor environments. 


\section{Indoor Environmental Quality (IEQ)}

People spend most of their time indoors. Australians and Americans typically spend approximately $90 \%$ and $92 \%$ of their time indoors, respectively $[5,6]$. Building occupants respond to an indoor environment through diverse stimuli, which can be visual, auditory, psychological, physical, dermal, olfactory, and respiratory. Therefore, for the health and well-being of the occupants, a good indoor environmental quality (IEQ) is important. IEQ is the product of various factors, and it therefore involves multidisciplinary approaches to solve problems related to IEQ, such as Sick Building Syndromes (SBS) which "may involve a multidimensional spectrum of impacts: social, political, health, and economy" [7].

In order to investigate the indoor environmental quality of any spaces, various factors shall be considered. The criteria for IEQ can be divided into five areas: thermal comfort, indoor air quality (IAQ), acoustic comfort, visual comfort and spatial comfort [8]. IAQ and thermal comfort are particularly important contributors to the indoor environmental quality. Therefore, ensuring that they are acceptable is essential in any building for the habitability of a space. This is especially the case in residential buildings where the occupants spend most of their time. Therefore, it is crucially important that a thorough study to be completed on the IEQ of the low cost housing type as it has the highest risk on poor IEQ.

\section{Methodology}

The methodology adopted in this study is a combination of site observation, and questionnaire survey. The questionnaire survey is the main research methodology which is supported by site observation. The initial stage is a site observation where the authors experienced the spaces within the flat, and then discussed on the layout. The objective of this method is for the authors to have general perception of the living condition in a low cost flat. Later, with an experience being in the low cost flat, the questionnaire survey was conducted while having informal discussions with the occupants.

The questionnaire survey consists of two sections: (a) questions on demography and information on flat, and (b) questions related to the perception of the indoor environment. The questions related to the indoor environment are questions concerning the room size, flat layout, ventilation, temperature (thermal), lighting and noise. The answers were rated using a 5-point Likert scale: 1-very unsatisfied, 2-unsatisfied, 3-neutral, 4-satisfied and 5-very satisfied. The survey covers 45 respondents, which was selected randomly. The respondents' ages are various, in which 14 respondents are below 25 years old, 29 respondents are between 25 to 45 years old and 2 respondents are above 45 years old. Out of the 45 respondents, 25 are males and 20 are females. In term of marital status, 32 respondents have married, whereas the other 13 respondents are still single. Meanwhile, it is also found that $60 \%$ of the respondents have been living in the flat for more than five years. In terms of the occupancy number, it is found that 34 respondents live with three to five family members, whereas the other 11 respondents have more than five family members in their houses. The survey was completed in four days, which was from 21 st to 24 th June 2013.

\section{Case Study}

The investigated low-cost flat (Taman Desa Sentosa Flat) (Figure 1) is situated in the Sepang District of Selangor, Malaysia. It is located approximately 30 kilometers from Kuala Lumpur, the capital city of Malaysia. It is neighbouring to Bandar Baru Bangi, and its distance to the Bandar Baru Bangi's commercial district is approximately 7 kilometres. The overall residential development at the site has seven residential blocks, which consist of 3 blocks of medium-cost apartment (the three blocks at the top) and four blocks of low-cost flat (the four blocks at the bottom). This study only focuses on the low-cost flat where the total number of unit is 280. Among the public facilities provided for the residents are praying hall, multipurpose hall, kindergarten and playground. 


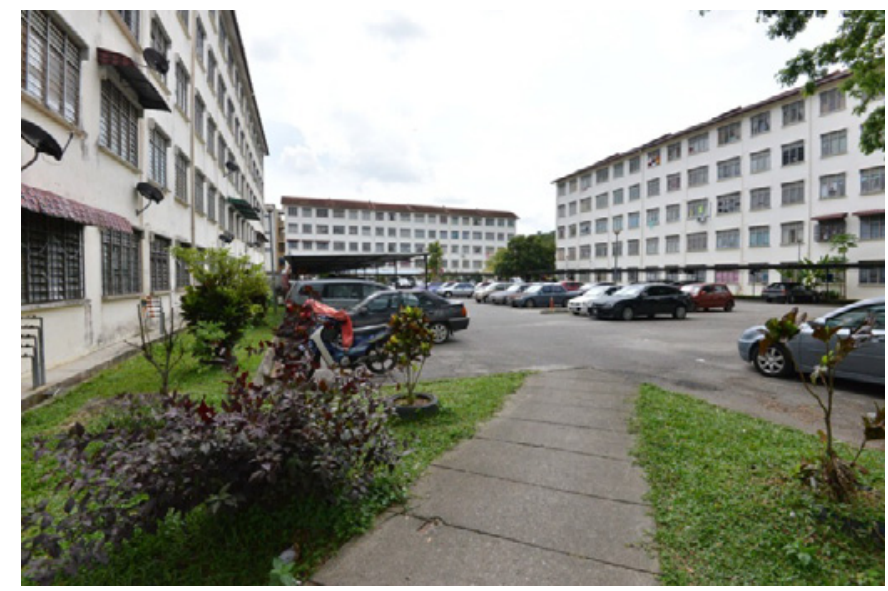

Figure 1: Taman Desa Sentosa Flat

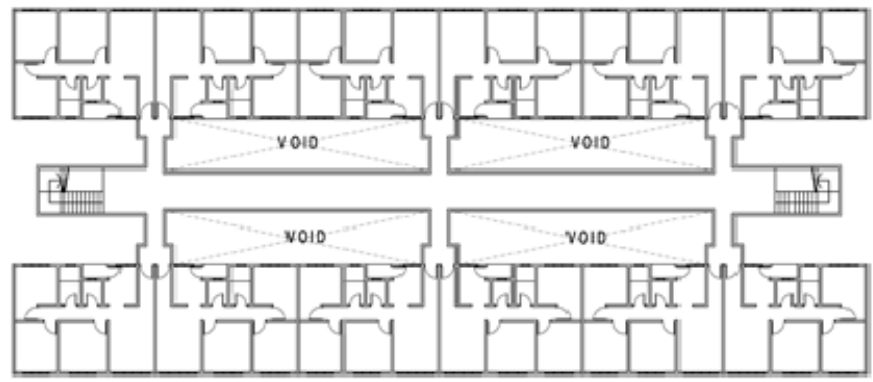

Figure 2: The layout plan of one of the apartment blocks

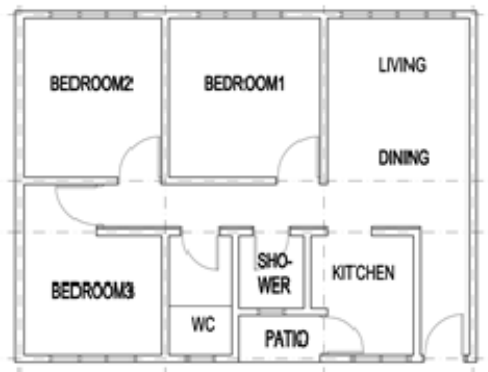

Figure 3: Flat unit floor plan

The selected block out of the four low-cost blocks as shown in Figure 2 has a typical typology of low-cost housing, which is commonly found in Malaysia. The overall layout of the flat is simple, thus may contribute to cost saving. The block has two rows of flat units with air well corridor, and a staircase at each end (Figure 2). Each row has six units, thus making each floor to have 12 units in total. It is a five-storey walk-up flat; hence the block in Figure 2 has 60 units. The provision of airwell contributes to better ventilation and daylight penetration for each unit.

The room sizes of the unit are too small for big family but adequate for small family. The smallest bedroom, is just enough for small bed with wardrobe and study table. The idea of separating water closet and shower room is appropriate for the three-bedroom unit flat. The floor plan of each unit (Figure 3) also has a simple layout where all spaces are located within a rectangular frame. The plan layout is also typical, which is commonly found in an apartment building, where the living/dining room is accessible directly from the entrance door. The kitchen is located next to the entrance door, but it is only accessible from the living/dining room. Generally, this layout is a comfortable layout where the private areas (toilet, shower room and bedrooms) are separated from the less private spaces (dining and living room).

In the context of natural ventilation, the layout allows good cross ventilation for the living/dining room as well as the kitchen. For the indoor temperature, the discussions with respondents suggest that the indoor spaces do not provide good thermal comfort; however, better thermal comfort is achieved with installation of ceiling fan. In terms of natural lighting, it is found that the living room, bedroom 1 and bedroom 2 have direct daylight penetration; whereas the kitchen, toilet, shower room and bedroom 3 only have secondary daylight via the provided air-well. Thus, it results in less natural lighting and darker condition compared to the other spaces. For the level of noise, during the visit on the afternoon of a working day, it was found that the surrounding area is quiet. 


\section{Analysis and Findings}

The aim of this study is to identify the satisfaction level of the residents of low-cost flats in Taman Desa Sentosa to the environment inside their houses. In addition, the availability of input from the respondents will indicate whether the quality of the indoor environment of their houses has met their requirements. Hence, the occupants were asked with some questions regarding to their perception of the room size, room layout, ventilation, temperature, lighting and noise disturbance.

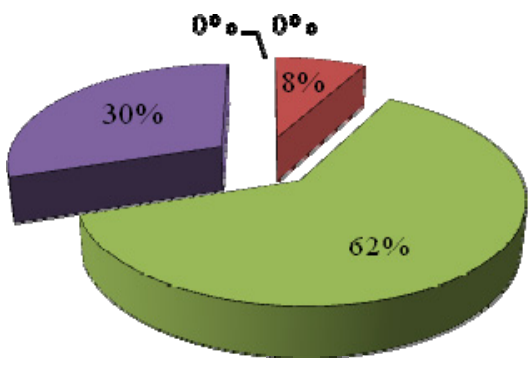

\section{Dyery unsatisfied}

口unsatisfied

口neutral

口satisfied

口very zatizfied

Figure 4: Satisfaction levels to the room size

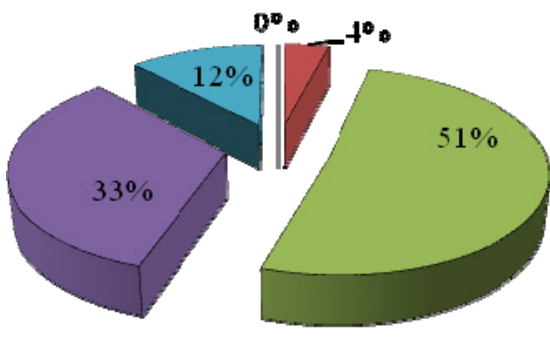

Dyery unsatisfied

口uusatisfied

Qneutral

口satisfied

Dyerysatixfied

Figure 5: Satisfaction levels to the room layout

The first question in Section B is the occupants' perception of the room size provided at the flats (Figure 4). Only four respondents (8\%) gave poor perception of the room size, whilst $62 \%$ or a total of 28 respondents felt neutral. Meanwhile, $30 \%$ or 13 respondents felt satisfied with the size of the internal spaces they occupied. The results also indicate that the occupants' perception of the room size was positive where around $92 \%$ expressed either neutral or satisfied, thus did not complain on the size of the room. Two possible reasons for these findings are they have become accustomed to the condition of the rooms, as well as they feel grateful to live in or own the flat though their incomes are low. It is found that $74 \%$ of the respondents have the household income of less than MYR2000. However, the combined percentage for neutral to very unsatisfied is the second highest (70\%) after the noise factor (Figure 9).

This study also found that $51 \%$ (23 people) of the respondents felt neutral with the plan layout of their houses, followed by 33\% (15 people) who felt satisfied. Interestingly, $12 \%$ or a total of 5 respondents felt very satisfied with the layout of their houses. This shows that the plan layout of the low-cost flat fulfills the needs of the occupants. The possible reasons for these findings are due to the layout arrangement which allows adequate natural lighting and ventilation, as well as successfully differentiates between the private and semi-private spaces. 


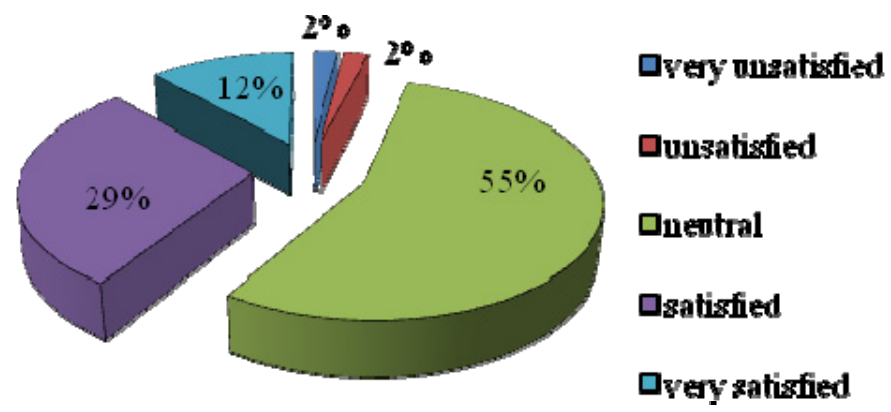

Figure 6: Satisfaction levels to the ventilation

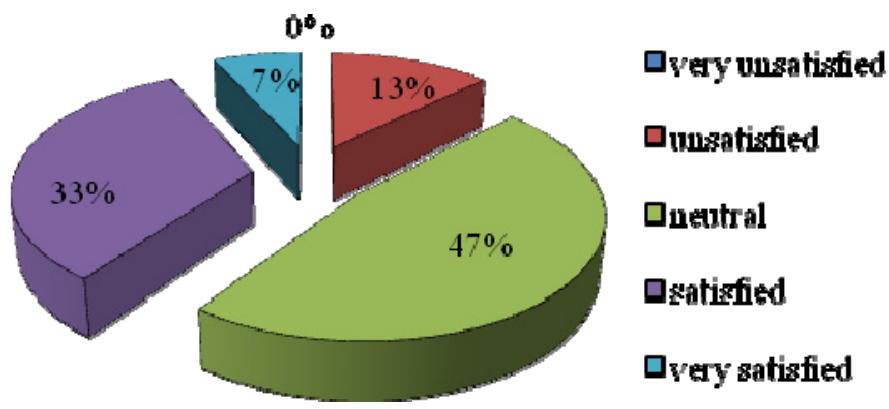

Figure 7: Satisfaction levels to the indoor temperature

In the case of perception of the ventilation performance (Figure 6), 25 respondents (55\%) chose neutral score, while 13 respondents $(29 \%)$ and 5 respondents $(12 \%)$ chose satisfied and very satisfied scores, respectively. However, there were also respondents who felt unsatisfied and very unsatisfied with the natural ventilation of the houses. Nevertheless, these numbers were very low compared to those who felt neutral and satisfied/very satisfied. The informal interviews with some respondents suggested that the reason to a large number of respondents felt satisfied with the ventilation performance is due to the presence of wide openings, which provide good natural ventilation.

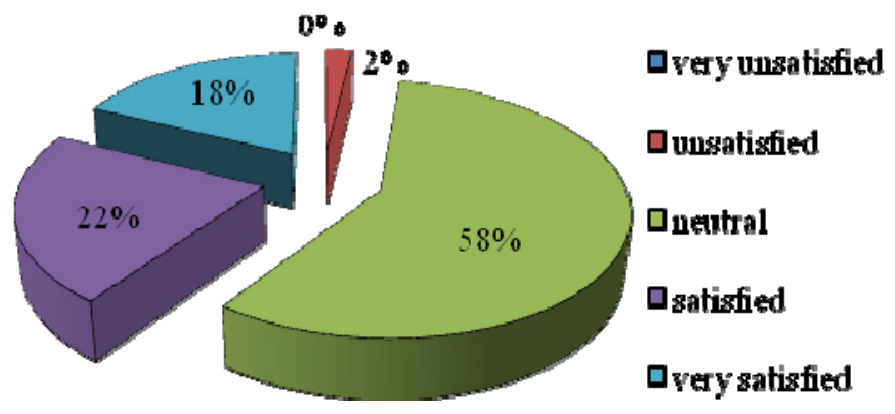

Figure 8: Satisfaction levels to the day lighting 


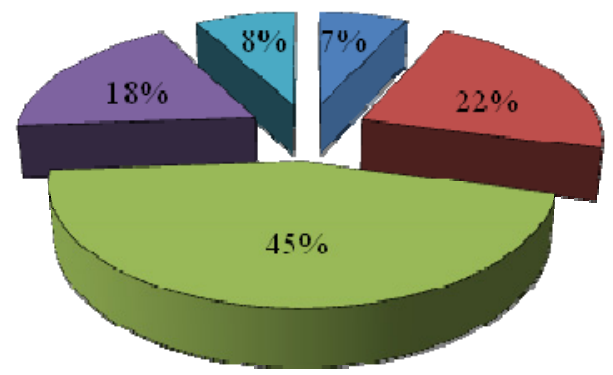

Dvery unsatistied

Dunsatisfied

Dueutral

Dsatizfied

口very zatizfied

Figure 9: Satisfaction levels to the noise disturbance

Regarding to the temperature for thermal comfort (Figure 7), it is found that 21 respondents (47\%) gave a neutral perception of temperature in their flat units. Meanwhile, 15 respondents (33\%) were satisfied with the indoor temperature, 3 respondents $(7 \%)$ were very satisfied, and only 6 respondents $(13 \%)$ chose unsatisfied score. The finding is almost similar to the perception of ventilation, where $87 \%$ of the respondents had chosen neutral, satisfied and very satisfied. This suggests that the thermal comfort of the flat units is acceptable to them. Even though only a very small number of respondents chose either unsatisfied or very unsatisfied for the ventilation and temperature, the percentage of respondents who installed air-conditioning system in their units were $22 \%$ (10 respondents). However, the percentage is still low compared to those who relied on mechanical fans and natural ventilation. This number suggests that majority of the respondents still do not feel the need to spend money on the air-conditioning system.

A total of 26 respondents or 58\% of the occupants gave a neutral perception of the day lighting in their houses. Meanwhile, 22\% (10 respondents) gave satisfactory perception, and followed by $18 \%$ ( 8 respondents) who felt very satisfactory. Generally, it can be concluded that most respondents either did not concern on the quality of day lighting in their houses, or they were satisfied with the current lighting. This finding suggests that the current indoor lighting is acceptable to the occupants. The contributing factors could be the provision of large windows on both sides of the unit, as well as a shallow depth of plan layout, which is only 7 meters. The shallow plan layout allows more penetration of day lighting into the indoor spaces.

The survey also found that $45 \%$ or a total of 20 respondents gave a neutral perception of noise disturbance. Meanwhile, $18 \%$ or a total of 8 respondents gave satisfactory perception; followed by another $8 \%$ (4 respondents) who expressed very satisfied to the noise interference. On the other hand, there were $22 \%$ (10 respondents) who felt unsatisfied with the noise in the housing and 7\% (3 respondents) who felt very unsatisfied. This amount is greater than the respondents who expressed satisfied or very satisfied with the noise issue. From the authors' observation and informal interviews, it is certain that the main reason behind this issue is due to the noise pollution from the motorcycles that had been parked close to the units.

\section{Conclusions}

The study concludes that the indoor environmental quality in the selected low-cost flat is acceptable by the residents. This is apparent from all findings, except the noise factor. This finding that suggests the IEQ of low-cost housing is acceptable by residents is similar to the finding by Abdul Ghani [2] which found that, in general, the residents in low-cost housing in two states in Malaysia (Penang and Terengganu) were generally satisfied with dwelling units. However, it is important to note that the second worst perception is on the room size. This is due to the small size of the unit which is less appropriate for large family. This finding is similar to finding by Mohit et al. [1] which suggests that larger unit shall be provided for large families.

Therefore, if actions are to be made to improve the quality of the indoor environment for the selected low-cost housing, the priority shall be given to the control of noise pollution (particularly the 
noise caused by the illegally parked motorcycles) and. It is also important to note that even though the study shows that most of the residents are either being neutral or satisfied/very satisfied, this finding may not exactly describe the real quality of the indoor spaces, unless proper measurements are made.

The reason for the positive outcome could be due to the adaptation of the residents to the indoor environment of their flat units, thus making them to feel neutral or comfort. Therefore, it is important in the future to conduct proper measurements to the indoor environment of the flat units. There is also a limitation in this study where only a single type of low-cost flat had been chosen for the survey. Hence, the authors intend to extend the research by including another two low-cost flats with different plan layouts, but still within Selangor. Hopefully, by the completion of the subsequent research, the outcomes could better describe the occupants' perception of indoor environment of low-cost flat.

\section{Acknowledgements}

This research was funded through the Fundamental Research Grant Scheme (FRGS/1/2012/TK07/UKM/03/3) of Ministry of Education of Malaysia; and the Research University Grant (GUP-2013-016) of Universiti Kebangsaan Malaysia.

\section{References}

1. Mohit, M.A., M. Ibrahim, and Y.R. Rashid, Assessment of residential satisfaction in newly designed public low-cost housing in Kuala Lumpur, Malaysia. Habitat International, 2010. 34 (1): p. 18-27.

2. Abdul Ghani, S., Neighbourhood factors in private low-cost housing in Malaysia. Habitat International, 2008. 32 (4): p. 485-493.

3. Idrus, N. and C.S. Ho, Affordable and quality housing through the lowcost housing provision in malaysia, in Seminar of Sustainable development and Governance. 2008: Japan.

4. Kementerian Wilayah Persekutuan dan Kesejahteraan Bandar, Dasar Rumah Mampu Milik Wilayah Persekutuan (RUMAWIP). 2013, Kementerian Wilayah Persekutuan dan Kesejahteraan Bandar: Putrajaya.

5. Australian Government, State of knowledge report: Air toxics and indoor air quality in Australia. 2001, Department of the Environment, Water, Heritage and the Arts.: Canberra.

6. Bernstein, J.A., et al., The health effects of nonindustrial indoor air pollution. Journal of Allergy and Clinical Immunology, 2008. 121 (3): p. 585-591.

7. Spengler, J.D., J.M. Samet, and J.F. McCarthy, Indoor air quality handbook. 2001, London: McGraw-Hill.

8. Woo, J.H., A conceptual framework for comfort evaluation focused on occupants' responses in work environments, in Indoor Air 2008: Proceedings of the 11th International Conference on Indoor Air Quality and Climate, P. Strom-Tejsen, et al., Editors. 2008: Copenhagen, Denmark. 